\title{
Health Care Analysis on Myocardial Revascularization in Patients with Chronic Coronary Artery Disease: The Multicenter REVASK Study: Design and Protocol
}

\author{
Andreas Beckmann ${ }^{1} \quad$ Eva-Maria Bitzer ${ }^{2} \quad$ Mareike Lederle $^{2}$ Peter Ihle ${ }^{3} \quad$ Jochen Walker $^{4}$ \\ Ursula Marshall $^{5}$ Dirk Horenkamp-Sonntag ${ }^{6}$ Steffen Schneider ${ }^{7}$ \\ Uwe Zeymer $^{7}$ for the REVASK Study Group
}

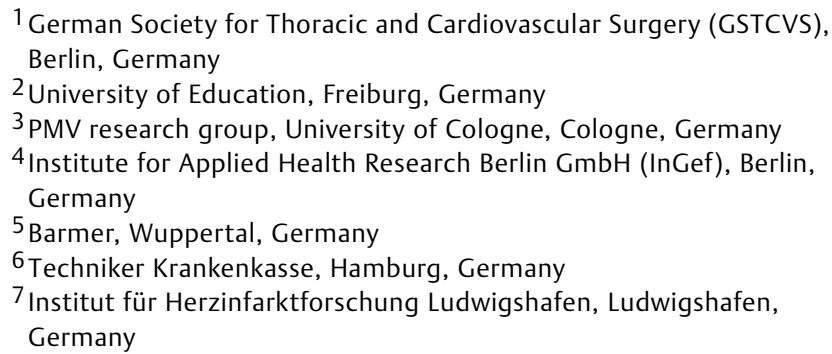

Address for correspondence Andreas Beckmann, MD, Deutsche Gesellschaft für Thorax-, Herz- und Gefäßchirurgie [DGTHG], Langenbeck-Virchow-Haus, Luisenstr. 58-59, 10117 Berlin, Germany (e-mail: gf@dgthg.de).

Thorac Cardiovasc Surg 2021;69:599-606.

\begin{abstract}
Keywords

- coronary heart disease

- coronary artery disease

- quality assurance

- health care research

- heart team

- guidelines

Coronary artery bypass grafting (CABG) and percutaneous coronary intervention $(\mathrm{PCl})$ are available for revascularization of coronary artery disease (CAD) with the aims to reduce cardiovascular morbidity and mortality and to improve disease-related quality of life in particular. The German National Care Guideline (NVL-CKHK) on chronic CAD recommends the establishment of so-called heart teams for decision making in myocardial revascularization to improve the quality of care. Preferred recommendations for $\mathrm{PCl}$ or $\mathrm{CABG}$ are given for different patient subgroups depending on patient characteristics, concomitant diseases, and coronary morphology. The myocardial revascularization study (REVASK) is a noninterventional cohort study on care of patients undergoing $\mathrm{PCl}$ or CABG based on retrospective statutory health insurance $(\mathrm{SHI})$ routine data, registry data from the German Cardiac Society (DGK) resp., the German Society for Thoracic and Cardiovascular Surgery (DGTHG), combined with prospective primary data collection from health care providers and patients. The primary goal is to investigate whether and to which extent heart teams, consisting of cardiologists and cardiac surgeons, increase guideline adherence in decision making for myocardial revascularization. Ultimately the study project aims to improve patient care in terms of decision making for appropriate myocardial revascularization. Through the consistent implementation of the German National Care Guideline on chronic Coronary Artery Disease (NVL-cKHK) and the European Guidelines on myocardial revascularization, the reduction of morbidity, mortality and the reduced need for subsequent revascularization procedures are also desirable from a health economics perspective.
\end{abstract}

received

October 1, 2020

accepted

October 1, 2020

published online

December 18, 2020
DOI https://doi.org/ 10.1055/s-0040-1721391. ISSN $0171-6425$.

\footnotetext{
(C) 2020. The Author(s).

This is an open access article published by Thieme under the terms of the Creative Commons Attribution-NonDerivative-NonCommercial-License, permitting copying and reproduction so long as the original work is given appropriate credit. Contents may not be used for commercial purposes, or adapted, remixed, transformed or built upon. (https://creativecommons.org/ licenses/by-nc-nd/4.0/) Georg Thieme Verlag KG, Rüdigerstraße 14, 70469 Stuttgart, Germany
} 


\section{Introduction}

The German National Care Guideline on chronic Coronary Artery Disease (NVL-cKHK) and the European Guidelines on myocardial revascularization recommend the establishment of interprofessional decision-making structures and processes for myocardial revascularization by heart teams, consisting of cardiologists and cardiac surgeons, to improve the quality of care. ${ }^{1-3}$ For the treatment of significant coronary artery disease (CAD), beside optimal medical therapy, percutaneous coronary intervention (PCI), and coronary artery bypass grafting (CABG) are available with the therapeutic goals to reduce cardiovascular morbidity and mortality and to improve disease-related quality of life. In Germany, $\mathrm{PCI}$ is by far the most frequently used revascularization therapy (ratio of PCI:CABG $=10: 1)^{4,5}$ However, there are scarce data on the appropriateness of revascularization procedures in Germany. ${ }^{6,7}$

According to the NVL-cKHK, various patients characteristics, concomitant diseases, and coronary anatomy should be taken into account for the right decision for a revascularization procedure. ${ }^{1}$ These include cardiac related features (left ventricular ejection fraction, left main stenosis, single- or multivessel disease, chronic coronary artery occlusion, and peculiarities of calcifications) and noncardiac patient characteristics (age, renal function, diabetes mellitus, and other concomitant diseases such as lung diseases). This results in numerous patient subgroups for which specific recommendations for the preferred revascularization procedure exist. ${ }^{2}$

To the best of our knowledge, the German REVASK study is one of the first scientific investigations in the field of myocardial revascularization that combines primary pro- spective data analysis, including the patients' view with secondary retrospective routine data.

\section{Objectives}

The primary goal of the study is to investigate whether and to which extent structured interdisciplinary cooperation between cardiac surgeons and cardiologists (operationalized by the use of interdisciplinary heart teams) increases guidelines adherence in decision making on revascularization therapy. This is based on the hypothesis that consistent interprofessional and participatory decision-making structures and processes lead to decisions in compliance with current guidelines on myocardial revascularization (-Fig. 1). The focus lies on specific patient subgroups for whom the NVL-cKHK and the European Guidelines on myocardial revascularization primarily recommends a revascularization by either PCI (IA-IIIB) or CABG (IA; ( - Fig. 1). A comparison of $\mathrm{PCI}$ vs $\mathrm{CABG}$ in terms of patient outcome is not the aim of this investigation.

\section{Material/Methodology/Study Design}

The observational study is based on statutory health insurance (SHI) providers data of BARMER, Techniker Kasse (TK), and a data pool of several craft guild and company health insurance funds from the Institute for Applied Health Care Research (InGef; 6 million SHI patients). In addition to these secondary analyses of health care provider claims the REVASK study will prospectively evaluate primary data from service providers and patients focused on the adherence to current scientific guidelines (-Fig. 2 ).

\section{Stable Multi-vessel or Left Main Coronary Artery Disease With Suitable Anatomy for PCl and CABG and Clinical Eligibility for either PCI or CABG}

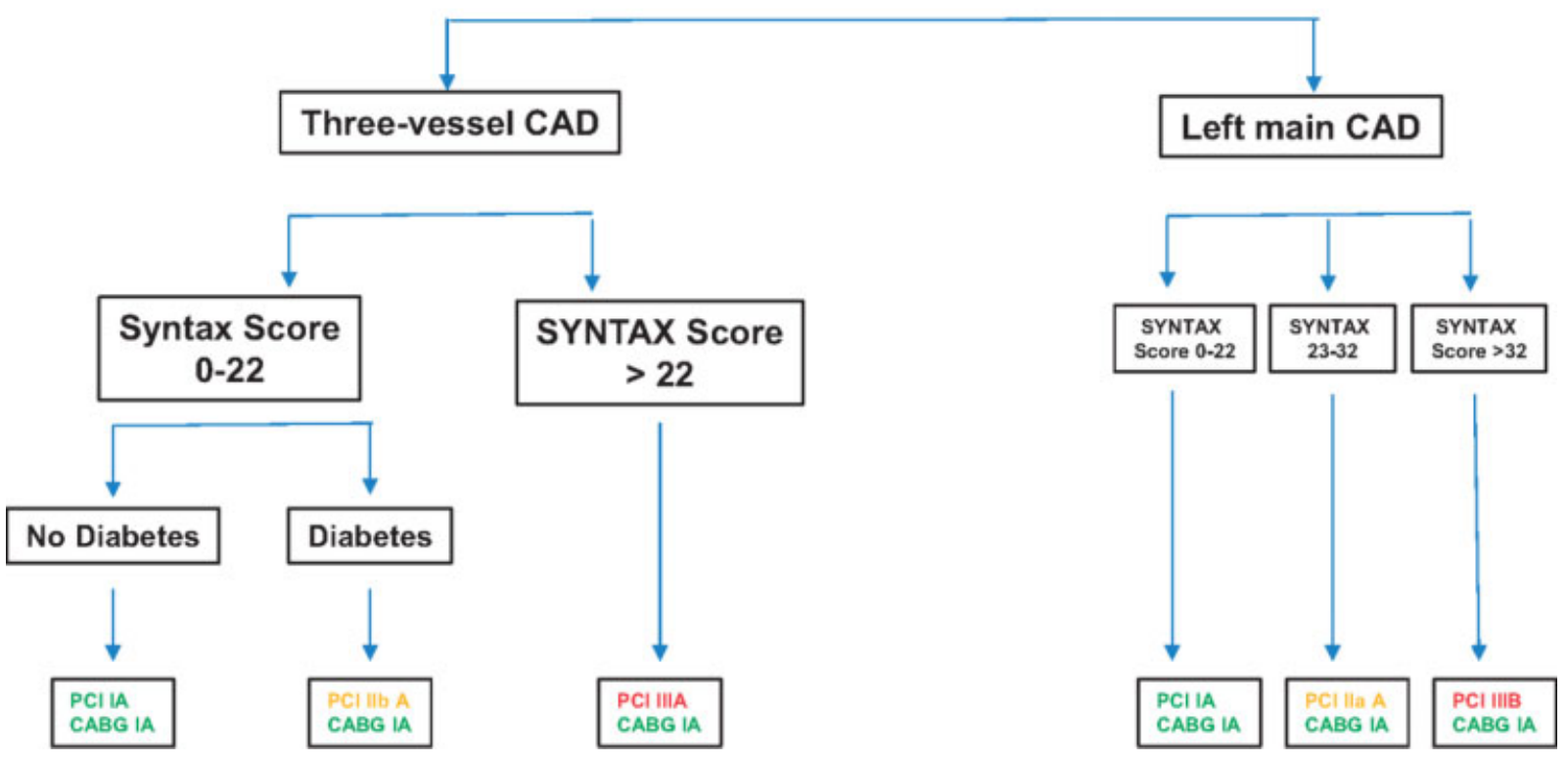

Fig. 1 Algorithm-choice of revascularization. Reprinted with permission by OUP Eur Heart J, Volume 40, Issue 2; 07 January 2019, Pages 204-212, https:// doi.org/10.1093/eurheartj/ehy532; CAD, coronary artery disease; PCI, percutaneous coronary intervention; CABG, coronary artery bypass grafting. 


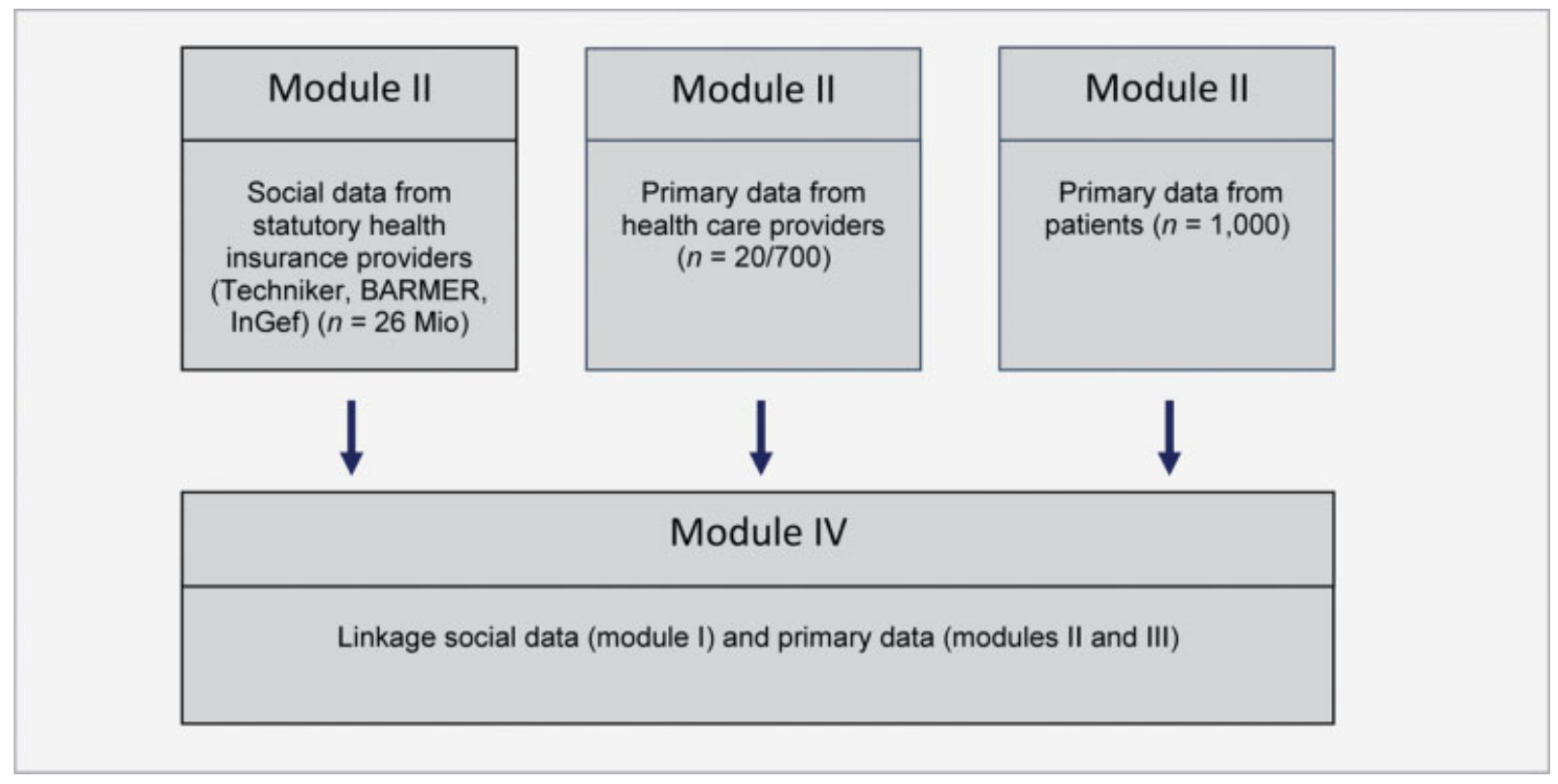

Fig. 2 REVASK study design-overview.

Patients' inclusion criteria are chronic coronary artery disease in the sense of a two- or three-vessel resp. left main disease, isolated $\mathrm{CABG}$ or $\mathrm{PCI}$, and statutory health insurance at prespecified German health insurance companies (BARMER or TK).

The study consists of four modules presented here ( - Fig. $\mathbf{3}$ ).

\section{Module I: Care Situation Analyses Based on Routine SHI Data}

Routine data from BARMER, TK, and InGef, as well as registry data from the DGK and DGTHG, will serve as the basis for the analyses that include insured patients with CAD who underwent a myocardial revascularization procedure.

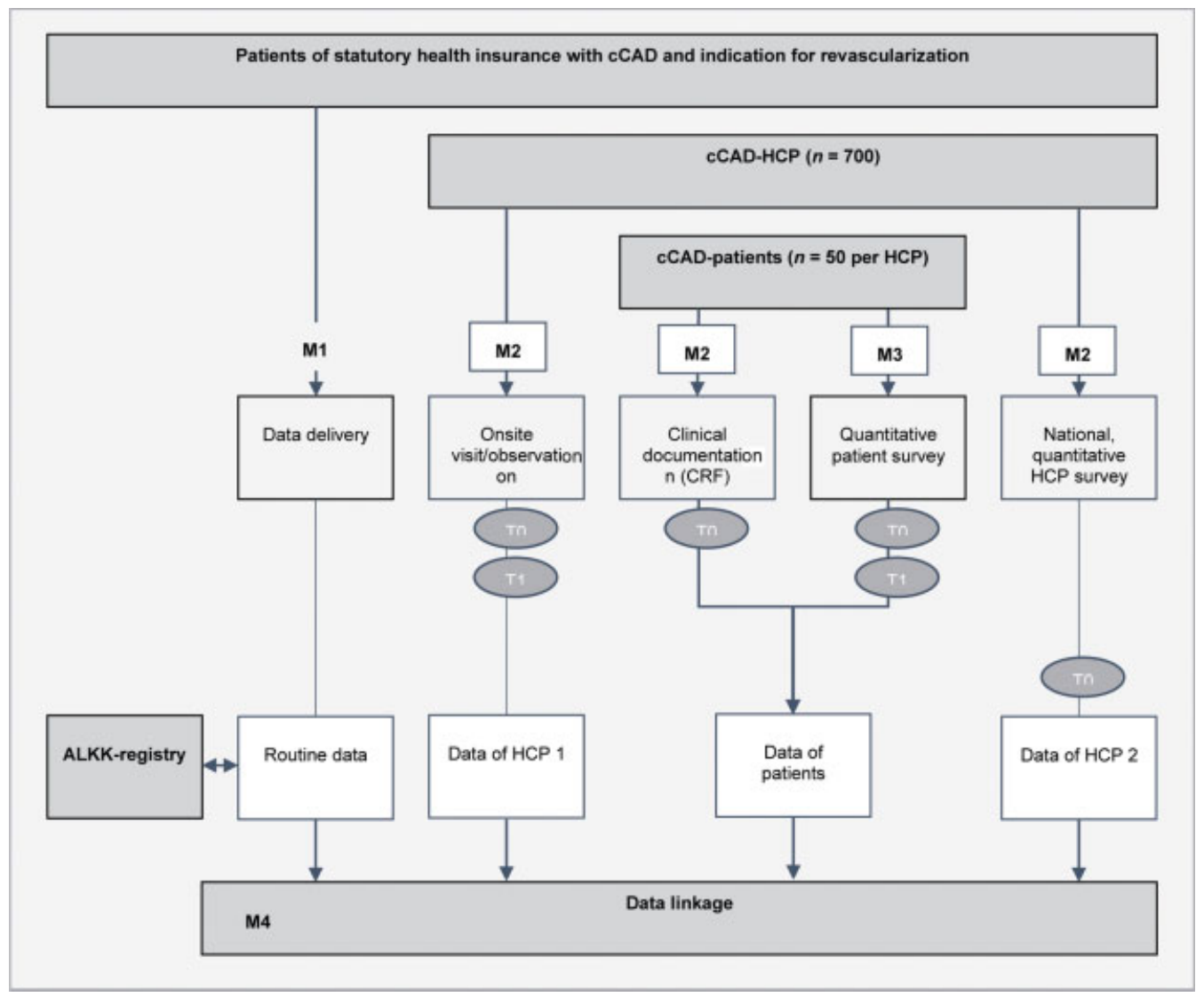

Fig. 3 REVASK study design-details. CCAD, chronic coronary artery disease; CRF, case report form; HCP, health care provider; M, module. ALKK, Arbeitsgemeinschaft leitende kardiologische Krankenhausärzte. 


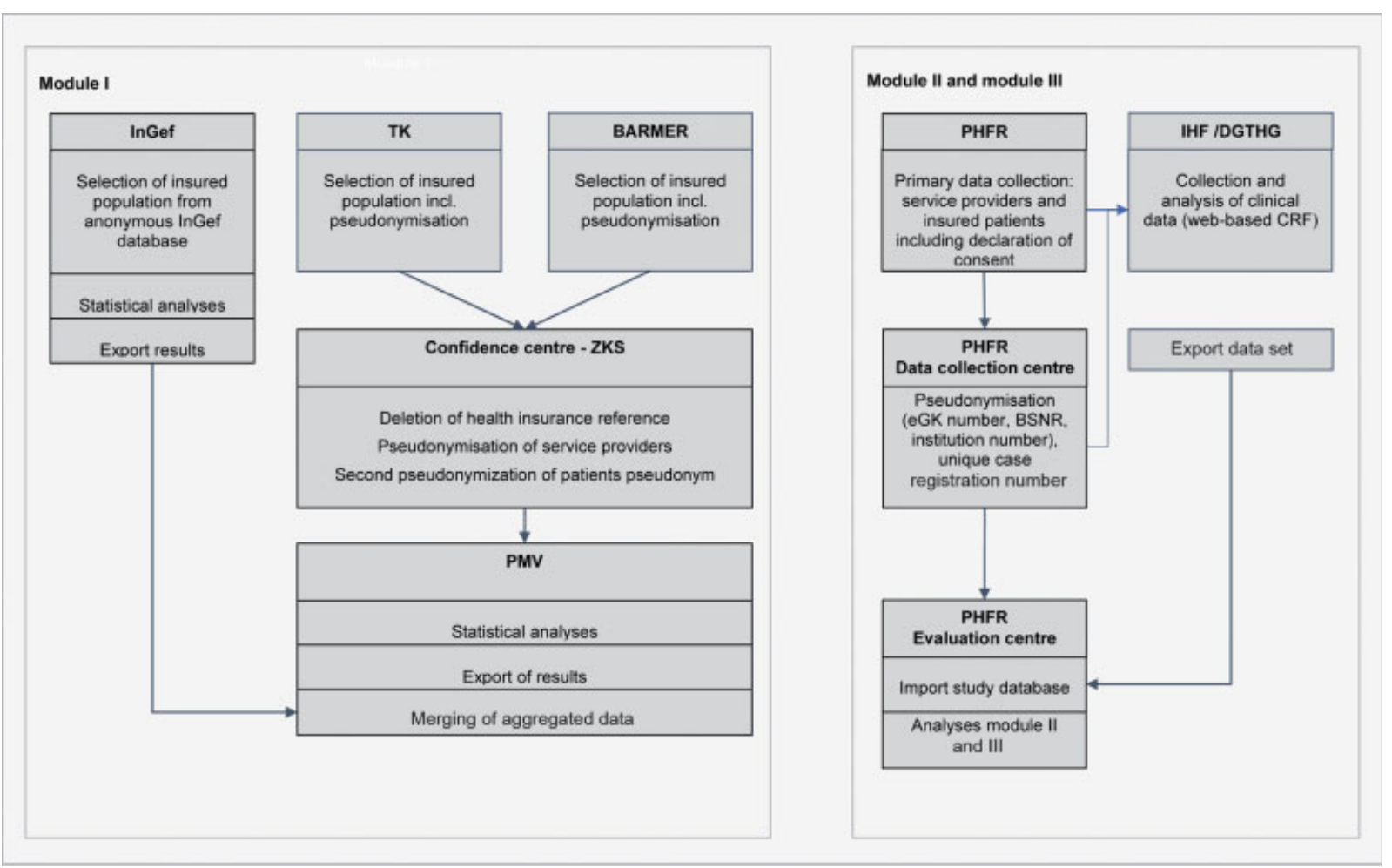

Fig. 4 REVASK data flow/management modules I-III. CRF, case report form; DGTHG, German Society for Thoracic and Cardiovascular Surgery; PHFR, data collection center of the University of Education Freiburg; ZKS, Centre for Clinical Studies, University of Cologne.

The aim of the first module (-Fig. 4) is a descriptive, population-based analysis of PCI and CABG rates in chronic CAD in Germany. In detail, this will focus on annual numbers of CABG or PCI in different supply sectors, care situations, regional variations in Germany, and patient contacts with medical specialists for Cardiac Surgery and Cardiology. Furthermore, a routine data investigation will be performed to evaluate to which extent specific patient subgroups underwent a guideline-recommended CABG procedure, especially against the background that the influential Syntax score $(\mathrm{SyS})^{8}$ is not available from routine data. Finally, a network analysis will illustrate typical treatment procedures starting from the initial diagnosis to the first invasive myocardial revascularization. Various methods of machine learning, such as gradient boosting and stability selection, are used to identify these pathways.

\section{Data Processing Module I}

Data of insured persons with documented CAD who underwent myocardial revascularization therapy are examined. Selected German physicians' fee schedule items (GOP) and German operation and procedure codes (OPS; adaption of the International Classification of Procedures in Medicine [ICPM]) serve as inclusion criteria ( - Table 1 ). Further relevant variables include data on the insured population, outand inpatient treatment, outpatient medical care, prescription data, and incapacity to work data including sick benefits. The analyses are based on the guidelines and recommendations formulated for the performance of secondary data analyses (Good Practice Secondary Data Analysis). ${ }^{9-11}$ First
Table 1 Selected German physicians fee schedule items (GOP)/German operation and procedure code (OPS)

\begin{tabular}{|l|l|}
\hline GOP & \\
\hline 34292 & $\begin{array}{l}\text { Zuschlag zu der Gebührenordnungsposition } \\
34291 \\
\text { bei Durchführung einer interventionellen } \\
\text { Maßnahme (z. B. PTCA, Stent) }\end{array}$ \\
\hline OPS & $\begin{array}{l}\text { Desobliteration (Endarteriektomie) } \\
\text { der Koronararterien }\end{array}$ \\
\hline $5-360$ & Anlegen eines aortokoronaren Bypass \\
\hline $5-361$ & $\begin{array}{l}\text { Anlegen eines aortokoronaren Bypass } \\
\text { durch minimalinvasive Technik }\end{array}$ \\
\hline $5-362$ & Andere Revaskularisation des Herzens \\
\hline $5-363$ & Rekonstruktion des Koronarostiums \\
\hline $5-369.3$ & $\begin{array}{l}\text { Perkutan-transluminale Gefäßintervention } \\
\text { an Herz und Koronargefäßen }\end{array}$ \\
\hline $8-837$ &
\end{tabular}

the routine SHI data from the health insurance funds are transmitted to the Confidence Centre (Centre for Clinical Studies, University of Cologne; ZKS) for pseudonymization. Then the data pool is forwarded to primary medical care (PMV) research group at university cologne (PMV) for specific insured database import and preparation for different analyses (SQL Server Management Studio, SAS Enterprise Guide, and R-Studio). In a separate step, the aggregated result sets of InGef are pooled with those of TK and BARMER by PMV. 


\section{Module II: Decision-Making Processes: Perspective of Health Care Providers}

The aim of the second module ( - Fig. 4 ) is to gain an in-depth and broad insight into the decision structures and processes for myocardial revascularization with a focus on heart team structures $^{12-17}$ and the application of the SyS (guideline recommendation IB) in everyday clinical practice. ${ }^{8}$ This module covers two phases: phase I with a qualitative indepth analysis of a selected sample of health care institutions. Thereby actual insights on decision paths care (pre-, intra-, and postprocedural) for PCI or CABG at the health care providers are obtained. In phase II, a large nationwide quantitative survey of institutions, providing myocardial revascularization procedures, will be performed.

For phase I, high-volume providers from different treatment settings are recruited as follows: outpatient cardiology practices with or without connection to a hospital (settings 1 and 2), hospitals with a cardiology but no cardiac surgery department (setting 3), and hospitals with cardiology and cardiac surgery departments (setting 4 ). The data collection in the first phase covers the following three:

1. A preparatory written survey concerning medical staff, technical equipment, and the workflow such as interdisciplinary cooperation and communication pathways within the team and with the patients.

2. An on-site audit (1-2 days) with qualitative guidelinebased expert interview with relevant and knowledgeable staff members, preferably members of the heart team.

3. A web-based case report form (CRF) survey of 25 resp. 75 patients from each institution consisting of patient characteristics, concomitant diseases verification of myocardial ischemia, and coronary anatomy.

The survey (1) will be evaluated descriptively using SPSS25 IBM Corp., United States. The documents provided by the institutions, the discussion and observation notes from the on-site audit (2) will be evaluated with MAXQDA
2020 VERBI GmbH Berlin as part of a document analysis, while the analysis of the diagnostic findings are performed via the web-based CRF system.

Based on the results of the three data collections (1-3), a standardized survey on decision-making processes and structures in myocardial revascularization therapy will be developed and applied in phase 2 . Thereafter a nationwide survey of all patient care providers from the above mentioned four settings will be conducted.

In summary, we expect a clear understanding of the workflow regarding patients care for myocardial revascularization in different treatment settings, including facilitators for and barriers against guideline adherence.

\section{Module III: Decision-Making Process from the Patients' Perspective}

In module III, a standardized longitudinal patient survey before and six months after the revascularization therapy will be conducted ( - Fig. 4). The aims of this survey are to evaluate how patients perceive the decision-making process in the context of their myocardial revascularization and to explore the role of the treatment settings against other determinants (i.e., age and gender).

A total of 1,000 patients via setting 1 to 4 (phase 1 module 2 ) will be recruited. In outpatient institutions (settings 1 and 2) at least 25 and in inpatient institutions (setting 3 and 4 ), a minimum of 75 patients per institution will be recruited. The staff of the recruiting institutions will include patients with an indication for isolated coronary angiography, isolated PCI, combined angiography and PCI or CABG. Written informed patients consent has to be obtained before enrolment.

For this part of the survey, established instruments of participatory decision-making, satisfaction with the decision and patient-reported endpoints (disease-specific quality of life) are used. ${ }^{18,19}$ On this, we follow the recommendations of the International Consortium for Health Outcomes Measurement (ICHOM) on standardized outcome measurement for patients with CAD. ${ }^{20}$ - Table 2 gives an overview of the

Table 2 Patient survey decision making

\begin{tabular}{|c|c|c|}
\hline Dimension & Assessment & Items \\
\hline $\begin{array}{l}\text { Treatment } \\
\text { options }\end{array}$ & Original items & \\
\hline \multirow[t]{2}{*}{$\begin{array}{l}\text { Decision } \\
\text { making }\end{array}$} & Decisional conflict scale (DCS) & $\begin{array}{l}16 \text { items, 5-point Likert's scale with response } \\
\text { categories from "strongly agree" to "strongly disagree" }\end{array}$ \\
\hline & $\begin{array}{l}\text { The 9-item shared decision making } \\
\text { questionnaire (SDM-Q-9) }\end{array}$ & $\begin{array}{l}\text { Nine items, 6-point Likert's scale with response } \\
\text { categories from "completely disagree" to "completely agree" }\end{array}$ \\
\hline Anxiety & $\begin{array}{l}\text { Amsterdam preoperative anxiety } \\
\text { and information scale (APAIS) }\end{array}$ & $\begin{array}{l}\text { Six items, with 6-point response categories } \\
\text { from "not at all" to "extremely" }\end{array}$ \\
\hline \multirow[t]{3}{*}{ Quality of life } & Seattle angina questionnaire (SAQ-7) & Seven items, with 6-point response categories \\
\hline & Patient health questionnaire (PHQ-4) & $\begin{array}{l}\text { Four items, with four point response categories from } \\
\text { "not at all" to "nearly every day" }\end{array}$ \\
\hline & $\begin{array}{l}\text { SOEP: Socio-Economic Panel version } \\
\text { of the Short Form } 12 \text { (SF-12) }\end{array}$ & Four questions, different response categories \\
\hline Social support & Berlin social support scales (BSSS) & $\begin{array}{l}\text { Eight items, 4-point Likert's scale with response } \\
\text { categories from "wrong" to "correct exactly" }\end{array}$ \\
\hline
\end{tabular}


variables assessed in the patient survey on decision making in myocardial revascularization. ${ }^{21-26}$ In addition, sociodemographic factors, such as year of birth, sex, comorbidities, highest educational qualification, highest professional qualification, employment status, and migration status will be collected.

Taking clustered data into account (similarity of patients from the same treatment institution vs. patients from different health care sectors) various analyses using IBM SPSS ${ }^{\circledR}$ and multilevel analysis/hierarchical linear modeling (HLM) will be applied.

\section{Module IV: Guidelines Adherence}

At present, there is scarce evidence of when, how, and under which conditions heart teams are used for interdisciplinary indication in Germany, and to which extent the decisions on therapeutic indication reached by a heart team differ from those made without (- Fig. 5).$^{12-17}$ Therefore, in module IV, the primary data from modules II and III are linked with selected routine SHI data from module I to assess guideline adherence. Furthermore, the dataset will be supplemented by the quality indicators collected in module III and the SyS calculated by patient care providers. For the study population from module II, the aim is to analyze information on the quality of interdisciplinary decision-making processes for the choice of myocardial revascularization, on the SyS and additional clinical information (e.g., verification of myocardial ischemia, instantaneous wave-free ration [iFR], and flow fractional reserve [FFR]). Furthermore, the
PCI versus CABG relationship in the heart team categories (module II) will be analyzed, primary data (module III) are linked to patient-specific SHI routine data (module IV) and further various analyses in multivariate statistical models are performed.

\section{Data Protection}

The study has been approved by the Federal Office for Social Security (AZ 116-8261-2443/2019), by the Ethics Review Committee of the University of Freiburg Medical Centre (number: 501/19) and is registered in the German Clinical Trials Register (ID: DRKS00022175).

All persons involved in the research project are bound to data secrecy ( $\$ 5$ BDSG and $\S 35$ SGB I) by the evaluating agency or the trust agency and the data receiving office. In addition, all employees involved in the evaluation are bound to medical confidentiality ${ }^{27}$.

The following independent organizations serve as independent data collection centers: ZKS and the data collection center of the University of Education Freiburg (PHFR).

The independent evaluation centers are PMV research group of the University of Cologne, PHFR, the Foundation Institute for Heart Attack Research in Luwigshafen, and the German Society for Thoracic and Cardiovascular Surgery in Berlin.

The confidential center at ZKS is physically and personally separated from the above-mentioned evaluation centers and

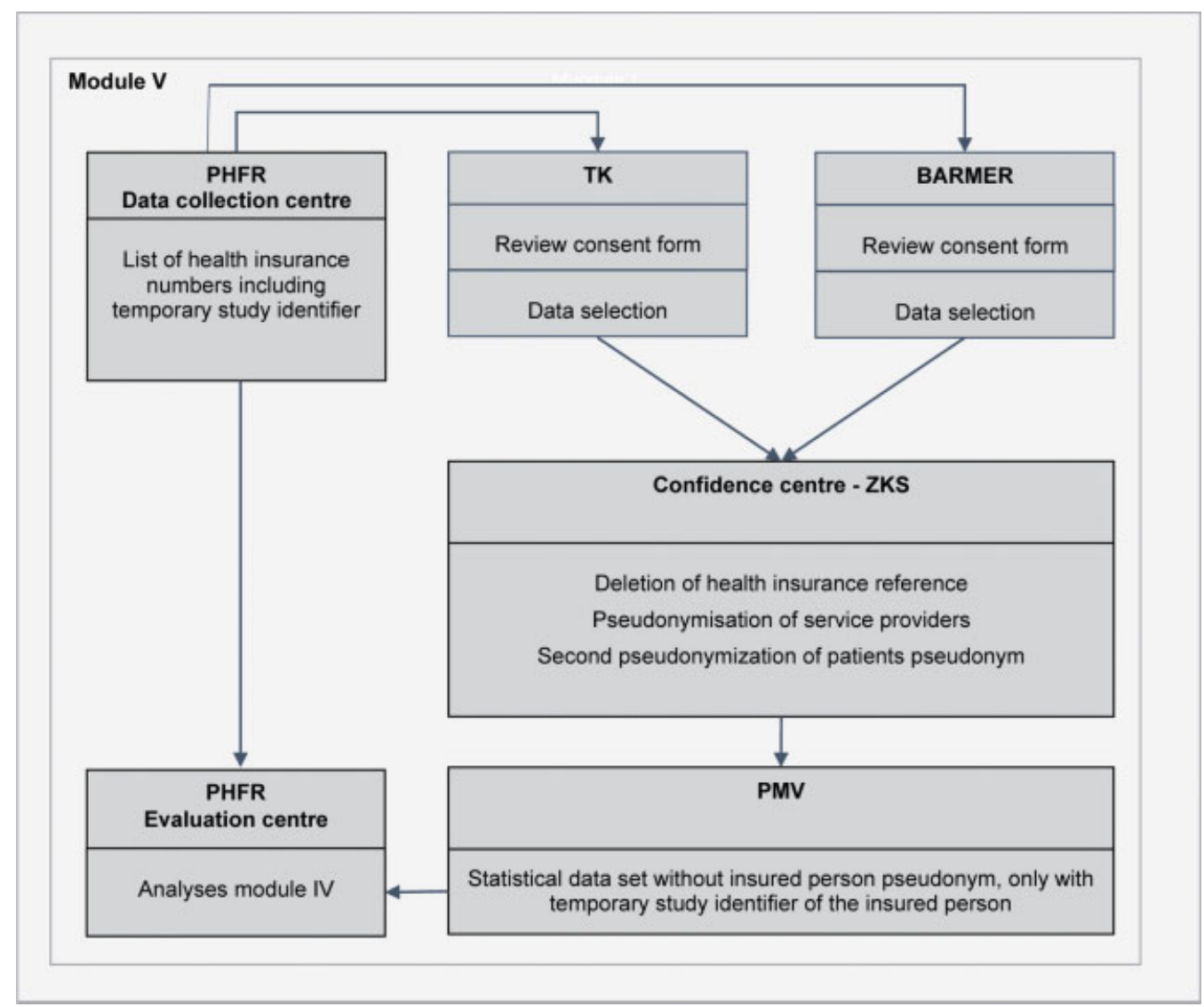

Fig. 5 REVASK data flow/management module IV. PHFR, data collection center of the University of Education Freiburg; ZKS, Centre for Clinical Studies, University of Cologne. 
is not bound by instructions and is independent of PMV. Its employees are not involved in data analysis.

The data collection center at PHFR, located in the Public Health and Health Education Department, pseudonymized the original data of the insured patients and the patient care providers before transmission to the PHFR evaluation center.

The CRF data inclusion is performed via a project-related case number, thereby data entry is pseudonymized. Based on the project-related case number, data analyses are performed at the Foundation Institute for Heart attack Research (IHF) and the DGTHG (de facto anonymized, since there is no link to the patient list). The statistical datasets are linked again to the survey data at patient level via project-related case number after transmission to the PHFR evaluation center.

\section{Discussion}

As a direct result of the project, findings will be available regarding the role of the heart team concerning decision making for myocardial revascularization and on the application of SyS I and II in everyday care. With these findings, guideline adherence might be optimized, thereby creating the prerequisites for increased adherence to guidelines in revascularization therapy. In addition, the project results may be transferred to everyday care at various levels. On the one hand, they could be used by health care providers to improve their processes with regard to participatory decision making to optimize the outcome of patients and to improve the overall quality of care for CAD. ${ }^{28-30}$ On the other hand, the results could be relevant for politics and legislation. Thus, the project may contribute to an improvement of patient-related outcome quality.

\section{Limitations}

Challenges arise, among other things, from the systemimmanent nature of routine SHI data. This primarily includes the lack of clinical data and uncertainties in the coding quality of billing data. This can be partially compensated by supplementing primary data. However, it must be taken into account that selection effects arise in the context of primary data collection, which are compensated by adjustment procedures.

Obtaining the consent of the insured persons in accordance with $§ 75$ SGB X results in methodological restrictions. Potential selection effects caused by a differentiation of the overall population of interest from the obtained sample with given consent cannot be excluded, a compensation by statistical methods is not possible. Since the relevant characteristics are often unknown, the weight of such a selection effect cannot be quantified.

In view of the importance for the patients concerned, the consent process is worthy of reflection. A critical examination of the frequency of cardiac catheter examinations, their determinants and, as far as possible, the appropriateness of the indication on the level of pseudonymized care data are useful and do not represent any impairment. On the other hand, obtaining consent, which would refer to examinations performed in the recent past, could lead to anxiety on the part of those affected and potential irritation, possibly even to a disruption of the doctor-patient relationship. In addition, the results of the REVASK study also obtain useful information for medical care or generates scientific contributions for guidelines and focus on the system level.

\section{Funding}

REVASK - care analysis for myocardial revascularization therapy in chronic CAD is funded by the German Innovation Fund (funding code: 01VSF18010). Details on the funding can be found on the project-specific website, www.revask.de, and on the website of the Federal Joint Committee, https://innovationsfonds.g-ba.de.

\section{Conflict of Interest}

None declared.

\section{References}

1 German Medical Association (BÄK), National Association of Statutory Health Insurance Physicians (KBV), Association of Scientific Medical Societies (AWMF) National Care Guideline Chronic CHD Accessed January 20, 2020 at: https://www.leitlinien.de/nvl/khk

2 Neumann FJ, Sousa-Uva M, Ahlsson A, et al; ESC Scientific Document Group. 2018 ESC/EACTS Guidelines on myocardial revascularization. Eur Heart J 2019;40(02):87-165

3 Neumann FJ, Byrne RA, Sibbing D, et al. Kommentar zu den „2018 ESC/EACTS Guidelines on Myocardial Revascularization“ der European Society of Cardiology (ESC) und der European Association for Cardio-Thoracic Surgery (EACTS). Kardiologe 2019;13:181-192

4 Federal Quality Report 2019 / Berlin: IQTIQ - Institute for Quality Assurance and Transparency in Health Care; 2020 Jan. Accessed on September 28, 2020 at: https://iqtig.org/qs-berichte/ bundesqualitaetsbericht

5 The German Heart Report 2019 Frankfurt am Main;. 2019 Accessed on November 21, 2020 at: http://www.herzstiftung. de/herzbericht

6 Beckmann A, Meyer R, Lewandowski J, Markewitz A, Gummert J. German Heart Surgery Report 2019: the annual updated registry of the German Society for Thoracic and Cardiovascular Surgery. Thorac Cardiovasc Surg 2020;68(04):263-276

7 Federal health reporting. Surgeries and procedures of inpatients in hospitals (place of residence/place of treatment) Classification features: Years, region, age, sex Accessed November 21, 2020 at: http://www.gbe-bund.de/oowa921-install/servlet/oowa/aw92/ dboowasys921.xwdevkit/xwd_init?gbe.isgbetol/xs_start_neu/ \&p_aid=i\&p_aid=81831931\&nummer=662\&p_sprache=D\&p_ indsp=-\&p_aid=13786543

8 Sianos G, Morel M-A, Kappetein AP, et al. The SYNTAX Score: an angiographic tool grading the complexity of coronary artery disease. EuroIntervention 2005;1(02):219-227

9 Swart E, Gothe H, Geyer S, et al; German Society for Social Medicine and Prevention German Society for Epidemiology. Good practice secondary data analysis (GPS): guidelines and recommendations. Gesundheitswesen 2015;77(02):120-126

10 Swart E, Bitzer E, Gothe Het al. A consensus German reporting standard for secondary data analyses, version 2 . Gesundheitswesen 2016;78(S 01):e145-e160

11 Working Group on Collection and Use of Secondary Data (AGENS) GPS-Good Practice in Secondary Data Analysis: Revision after Fundamental Reworking Accessed on September 28, 2020 from: https://www.dgepi.de/assets/Leitlinien-und-Empfehlungen/ Practice-in-Secondary-Data-Analysis.pdf 
12 Long J, Luckraz H, Thekkudan J, Maher A, Norell M. Heart team discussion in managing patients with coronary artery disease: outcome and reproducibility. Interact Cardiovasc Thorac Surg 2012;14(05):594-598

13 Chu D, Anastacio MM, Mulukutla SR, et al. Safety and efficacy of implementing a multidisciplinary heart team approach for revascularization in patients with complex coronary artery disease: an observational cohort pilot study. JAMA Surg 2014;149(11): 1109-1112

14 Bonzel T, Schächinger V, Dörge H. Description of a heart team approach to coronary revascularization and its beneficial longterm effect on clinical events after PCI. Clin Res Cardiol 2016;105 (05):388-400

15 Pavlidis AN, Perera D, Karamasis GV, et al. Implementation and consistency of Heart Team decision-making in complex coronary revascularisation. Int J Cardiol 2016;206:37-41

16 Sanchez CE, Dota A, Badhwar V, et al. Revascularization heart team recommendations as an adjunct to appropriate use criteria for coronary revascularization in patients with complex coronary artery disease. Catheter Cardiovasc Interv 2016;88(04): E103-E112

17 Domingues CT, Milojevic M, Thuijs DJFM, et al. Heart Team decision making and long-term outcomes for 1000 consecutive cases of coronary artery disease. Interact Cardiovasc Thorac Surg 2019;28(02):206-213

18 Scholl I, Kriston L, Härter M. PEF-FB-9-Fragebogen zur Partizipativen Entscheidungsfindung (revidierte 9-Item-Fassung). Klin Diagn Eval 2011;4:49

19 Spertus JA, Winder JA, Dewhurst TA, et al. Development and evaluation of the Seattle Angina Questionnaire: a new functional status measure for coronary artery disease. J Am Coll Cardiol 1995;25(02):333-341

20 McNamara RL, Spatz ES, Kelley TA, et al. Standardized outcome measurement for patients with coronary artery disease: consensus from the International Consortium for Health Outcomes Measurement (ICHOM). J Am Heart Assoc 2015;4(5, e00s1767): e001767

21 Buchholz A, Hölzel L, Kriston L, et al. Die Decisional Conflict Scale in deutscher Sprache (DCS-D) - Dimensionale Struktur in einer Stichprobe von Hausarztpatienten. Klin Diagn Eval 2011; 4:15-30

22 Berth H, Petrowski K, Balck F. Die Amsterdam Preoperative Anxiety and Information Scale (APAIS) - erste Erprobung einer deutschsprachigen Version. GMS Psycho-Social-Medicine 2007:4

23 Chan PS, Jones PG, Arnold SA, Spertus JA. Development and validation of a short version of the Seattle angina questionnaire. Circ Cardiovasc Qual Outcomes 2014;7(05):640-647

24 Kroenke K, Spitzer RL, Williams JBW, Löwe B. An ultra-brief screening scale for anxiety and depression: the PHQ-4. Psychosomatics 2009;50(06):613-621

25 Andersen HH, Mühlbacher A, Nübling M. Die SOEP-Version des SF 12 als Instrument gesundheitsökonomischer Analysen. 2007; ISSN: 1864-6689

26 Schulz U, Schwarzer R. Soziale Unterstützung bei der Krankheitsbewältigung: Die Berliner Social Support Skalen (BSSS). Diagnostica 2003;49:73-82

27 World Medical Association WMA Declaration of Helsinki - Ethical Principles for Medical Research Involving Human Subjects Accessed on September 28, 2020 from: https://www.wma.net/ policies-post/wma-declaration-of-helsinki-ethical-principlesfor-medical-research-involving-human-subjects/

28 Cohen DJ, Osnabrugge RL, Magnuson EA, et al; SYNTAX Trial Investigators. Cost-effectiveness of percutaneous coronary intervention with drug-eluting stents versus bypass surgery for patients with 3-vessel or left main coronary artery disease: final results from the Synergy Between Percutaneous Coronary Intervention With TAXUS and Cardiac Surgery (SYNTAX) trial. Circulation 2014;130(14):1146-1157

29 Magnuson EA, Farkouh ME, Fuster V, et al; FREEDOM Trial Investigators. Cost-effectiveness of percutaneous coronary intervention with drug eluting stents versus bypass surgery for patients with diabetes mellitus and multivessel coronary artery disease: results from the FREEDOM trial. Circulation 2013;127 (07):820-831

30 Tam DY, Dharma C, Rocha R, et al. Long-term survival after surgical or percutaneous revascularization in patients with diabetes and multivessel coronary disease. J Am Coll Cardiol 2020;76 (10):1153-1164 